\title{
OTIOLTOMTS
}

Revista de economía, empresa y sociedad

Dosier sobre economía colaborativa (y II)

Nuevas estrategias y dimensiones alternativas de la economía de plataforma

Coordinador: Lluís Alfons Garay Tamajón

NUEVAS ESTRATEGIAS

\section{Alojamientos desinfectados y cuerpos sanos: reflexiones sobre la respuesta de Airbnb a la pandemia}

\section{Maartje Roelofsen}

Universitat Oberta de Catalunya (UOC)

\section{Glaudio Minca}

Universidad de Bolonia

RESUMEN El presente artículo examina algunos de los principales cambios registrados en la política de viajes, los estándares y los protocolos de Airbnb desde que se iniciara la pandemia de COVID-19. Constituye una reflexión sobre cómo el clima de incertidumbre instalado desde la crisis sanitaria mundial, ha llevado a Airbnb a fomentar entre sus usuarios nuevas actitudes y valores relacionados con la flexibilidad, la adaptabilidad, la responsabilidad y el compromiso de largo plazo. Se analizan, en particular, los nuevos protocolos y medidas que han dado origen a una política uniforme y de transparencia en las cuestiones relacionadas con la salud y la seguridad, pero también en las interacciones sociales y los modos de comunicación personal, el trabajo, así como en el comportamiento diario de los anfitriones y los huéspedes de Airbnb. También se pone en relieve la manera en que los cambios aplicados en la plataforma han sido objeto de cuestionamientos, expresados mediante algunas protestas en contra de las nuevas medidas, las cuales fueron recogidas en el Airbnb Community Center. Por último, se presentan algunas observaciones sobre el desarrollo futuro del sistema de hospitalidad de Airbnb y sus posibles consecuencias para los viajes y el turismo en escenarios postpandémicos.

PALABRAS CLAVE Airbnb; COVID-19; desinfección; alojamiento; hospitalidad/hospedaje 


\title{
Sanitised homes and healthy bodies: reflections on Airbnb's response to the pandemic
}

\begin{abstract}
This paper examines some key changes to Airbnb's travel philosophy, protocols and standards since the outbreak of the COVID-19 pandemic. It reflects on how the climate of uncertainty imposed by the global health crisis has induced Airbnb to promote among its users a new ethos of flexibility, adaptability, liability and long-term commitment. In particular, we discuss how new protocols and regulatory measures have engendered a culture of uniformity and transparency regarding issues of health and safety, but also concerning social interactions, personal communication, labour, and the conduct of everyday life of Airbnb's hosts and guests. The article also highlights that the changes implemented by the platform have not gone unchallenged and how some of the protests against the new measures and protocols were manifested via the Airbnb Community Center. We conclude with a few considerations about possible future directions of the Airbnb hospitality machinery and their potential consequences on the post-pandemic landscapes of travel and tourism.
\end{abstract}

KEYWORDS Airbnb; COVID-19; sanitization; home; hospitality

\section{Introducción}

El futuro de Airbnb ha estado en el centro de vigorosos debates públicos y académicos desde el comienzo de la pandemia de COVID-19 (véase, por ejemplo, Dolnicar y Zare 2020; Glusac 2020; Schaal 2020). Algunas plataformas, y en particular, las plataformas de servicios de entrega a demanda, han capitalizado la crisis sanitaria con el incremento expansivo en su volumen de usuarios (Bosma et al. 2020). Pero, en cambio, Airbnb se ha visto atrapada en esta crisis que ha afectado a la industria del turismo y de la hostelería en general. Este sector es uno de los más afectados por el virus (UNWTO 2020) y es considerado como uno de sus vectores de propagación (laquinto 2020). Los espacios cerrados en los aviones, los barcos de crucero y las diversas modalidades de alojamiento turístico, incluidos los «alojamientos compartidos", fueron sometidos a normas estrictas porque fueron identificados como los lugares en donde podrían producirse más contagios. Al igual que ocurrió con la mayoría de empresas turísticas desde que el virus empezara a extenderse por el mundo, Airbnb registró una anulación masiva de reservas debido a las restricciones a la movilidad individual, los confinamientos, el cierre de las fronteras y las reglas de distanciamiento social impuestas por las autoridades en los países afectados por la pandemia. Las enormes pérdidas en sus ingresos llevaron a la empresa a adoptar medidas de manejo de la crisis (véase Bosma 2020) tales como la suspensión de todas sus actividades de marketing, la aplicación de recortes salariales y el despido del 25 \% de su personal. Aun así, y a pesar del impacto de la pandemia en sus operaciones, la plataforma sigue siendo considerada como una de las empresas de hostelería de mayor valor a nivel mundial gracias a su capitalización en el mercado, un aspecto confirmado por el éxito de su salida en el mercado de valores en diciembre de 2020 (Allyn y Schneider 2020). Airbnb ha conseguido, en cierto modo, reinventarse a sí misma explorando nuevas maneras de capitalizar la vida diaria y los espacios íntimos de sus usuarios introduciendo algunos cambios en sus productos y servicios. Según ha observado Sarah Barns $(2020,101)$, es necesario mantenerse atentos a los cambios que las plataformas están efectuando, pues estos no son únicamente «una condición generalizada en el capitalismo de plataforma» sino un conjunto de intervenciones estratégicas de las compañías, cuyo fin es ejercer y mantener el control de sus mercados.

Basándonos en nuestros trabajos anteriores sobre Airbnb (Roelofsen 2018; Roelofsen y Minca 2018; Minca y Roelofsen 2019) y en otros estudios de plataformas turísticas, explicamos aquí brevemente la manera en que la 
pandemia ha puesto en cuestión la propia idea del «alojamiento compartido», lo cual ha dado lugar a una nueva "Cultura de la hospitalidad Airbnb» basada en la incertidumbre, el contagio y la desinfección. Para ello, hacemos un repaso de algunos de los principales cambios introducidos en el último año en la «política de viajes» de Airbnb, en sus protocolos y normas, sus términos y condiciones, y en su infraestructura digital. También hemos analizado 79 entradas de blog publicadas por la empresa en el Newsroom de Airbnb entre el 9 de octubre de 2019 y el 27 de enero de 2021, que explican en detalle los principales cambios realizados. A su vez, contraponemos a este análisis el examen de una selección de 31 comentarios de blog publicados por los anfitriones y usuarios de Airbnb en el Airbnb Community Center (en lo sucesivo, el ACC).

\section{Anfitriones responsables y flexibles y «alojamientos para estancias largas»}

El primer pronunciamiento oficial de Airbnb con motivo de la pandemia se dio a conocer a finales de febrero de 2020. En un anuncio aparecido en Airbnb News, la empresa anunció que seguía de cerca el brote de coronavirus y se concentró en ofrecer «ayuda de emergencia» como respuesta a las reservas que estaban siendo canceladas en forma masiva (Airbnb 2020). Con la activación de su «política de causas de fuerza mayor relativa al coronavirus», Airbnb permitió que tanto los anfitriones como los huéspedes cancelaran algunas reservas desde su plataforma sin que fueran aplicados los gastos ni las penalizaciones habituales. Esta medida tuvo un impacto adverso, particularmente en los anfitriones que antes estuvieron a favor de políticas estrictas o moderadas de cancelación y que, en circunstancias normales, habrían obtenido (parte) del importe pagado por el huésped sin importar que se hubiera producido o no su estancia.

El consecuente trastorno ocasionado a un número considerable de anfitriones llevó a estos a expresar su frustración por medio del ACC y de otros canales de comunicación. El ACC registró numerosas discusiones en las que el público se preguntaba si la compañía hubiera debido ser responsable, y de qué manera, del resarcimiento por las pérdidas ocasionadas. Una entrada que se hizo popular y generó un hilo con más de 600 respuestas, reclamaba que los costes de cancelación deberían ser al menos compartidos entre los anfitriones y los huéspedes. La discusión puso en evidencia que muchos anfitriones aprovecharon políticamente las circunstancias, y que utilizaron las redes sociales y el ACC de manera colectiva para poner el foco de atención en el funcionamiento y las responsabilidades de la plataforma. Esta estrategia (que tuvo un éxito moderado) ya había sido empleada anteriormente por los anfitriones para reclamar por la forma en que su trabajo estaba siendo configurado, regulado y organizado por el software de Airbnb (véase Minca y Roelofsen 2019; también Wilson et al. 2021). La principal crítica que se repetía en muchas de las entradas más recientes señalaba que Airbnb mantenía el derecho de control, redireccionamiento y capitalización del negocio del «alojamientos compartidos» que se generaba a través de su software, y al mismo tiempo, se exoneraba de toda responsabilidad en casos de fuerza mayor, absteniéndose de prestar a los anfitriones el apoyo o la protección que serían de esperar. Un grupo de anfitriones publicó peticiones para hacer responsable a la compañía, mientras que otros expresaron su intención de trasladar sus negocios de «alojamientos compartidos» a otras plataformas de alquiler por estancias cortas, animando a más miembros a hacer lo mismo. Sin proponérselo, los comentarios aparecidos en el ACC evidenciaron que la base de usuarios de Airbnb estaba conformada por personas que podían ser consideradas como «profesionales» con las más diversas aptitudes (Bosma 2021; Semi y Tonetta 2020). Basándose en estudios anteriormente encargados por la propia empresa, ésta a menudo ha señalado que sus usuarios son predominantemente «anfitriones que comparten la vivienda en la que viven» para así obtener unos ingresos suplementarios (por ejemplo, Airbnb 2017a; 2017b; 2018). Pero lo que en realidad emergía de los comentarios publicados en el blog es que existían numerosos miembros participantes en la discusión que dependían única o significativamente de sus ingresos en Airbnb para subsistir; y que algunas de estas personas administraban una oferta de alquiler variada y que alquilaban exclusivamente a turistas (véase Gil y Sequera 2020; Cocola-Gant y Gago 2019).

Sin duda, esta vibrante reacción hizo que Airbnb reconsiderase su estrategia de emergencia e ideara respuestas que fuesen mejor aceptadas por su base de usuarios. Pocas semanas después, y como pidiendo disculpas, la empresa estableció un fondo de ayuda de 250 millones de dólares a modo de compensación para los anfitrio- 
nes más afectados por la decisión de suspender la política de cancelaciones (Airbnb 2020a). Además, se creó un Fondo de Emergencia para los Superhosts que eran «especialmente dependientes» de los ingresos que obtienen en Airbnb para «llegar a fin de mes» (Ibid.) Finalmente, unas 8.700 personas recibieron financiación a través de este fondo y se publicaron en el Airbnb News los casos de algunas de las personas que fueron indemnizadas (Airbnb 2020b). En la misma noticia, el director ejecutivo de la compañía, Brian Chesky, reiteraba a los anfitriones que Airbnb se comprometía a «restaurar nuestra sociedad", poniendo el énfasis en la manera en que los alojamientos de Airbnb podían ser también muy útiles para dar respuesta a la crisis. De hecho, se alentó a los anfitriones a ofrecer sus viviendas de forma gratuita, o a bajo coste, para el personal sanitario de emergencias y de primera línea que trabajaba en la pandemia. Aunque todavía queda por investigar en qué medida ese gesto filantrópico ha sido puesto en práctica por los anfitriones, Airbnb se mostró como un símbolo de «institución urbana» que promovía el uso de las propiedades de sus usuarios y su hospitalidad, los cuales constituyen activos urbanos esenciales en tiempos de crisis (véase Van Doorn 2020). Al hacerlo, Airbnb pone implícitamente de manifiesto su vigoroso papel como actor social en la gobernanza de numerosas ciudades, también en tiempos de crisis como la que ha provocado la pandemia.

Tras la controversia creada, y con miras a operar en un nuevo escenario de riesgos ocasionados por la COVID, la empresa publicó en su blog varias piezas en las que aclaraba y reafirmaba cuáles eran sus responsabilidades con los usuarios. Se informaba que la plataforma de Airbnb promovía un modelo de negocio con «pocos activos" que tenía una «base comunitaria» y se apoyaba en el «impulso de las personas». Con ello se diferenciaban de los modelos de negocio tradicionales, que son jerárquicos y no admiten contrapartes, como ocurre en las «grandes corporaciones con muchos activos, que están verticalmente integradas y capturan la mayor parte de los beneficios económicos que se generan» (Airbnb 2020c). En sus publicaciones, Airbnb aclaraba que la empresa era fundamentalmente responsable de su infraestructura «digital». Por ser la proveedora del software que posibilita un «mercado de dos caras», la empresa señalaba su «compromiso en hacer todo lo posible por dar apoyo razonable a ambas partes, y siendo coherentes con el funcionamiento de este mercado» (Ibid.). La insistencia de Airbnb en puntualizar su exclusivo papel de proveedor del software, y su ambigüedad al expresarse acerca de la naturaleza del «apoyo» que presta a los usuarios, es similar a las estrategias adoptadas por otras plataformas a demanda. Dichas estrategias ya han sido antes empleadas para obligar a los usuarios a asumir los riesgos y responsabilidades que conlleva el trabajo con el que ellos hacen posible que las plataformas obtengan beneficios. (véase van Doorn 2017).

Desde el inicio de la pandemia, Airbnb ha efectuado cambios adicionales en su infraestructura digital que obligan al usuario a cumplir con unos niveles más altos de flexibilidad y «profesionalidad» mientras que la empresa se exonera nuevamente de cualquier responsabilidad. Por ejemplo, se han introducido una serie de herramientas y programas de «Reservas más flexibles», las cuales han sido desarrolladas para "asistir a los anfitriones y los huéspedes en tiempos de incertidumbre con el fin atender cualquier necesidad de cancelar o postergar sus ofertas de alojamiento o sus planes de viaje» (Airbnb 2020d). Airbnb ha ofrecido recompensas para los anfitriones que adopten las políticas de cancelación más «flexibles» en este programa, permitiendo que «sus ofertas sean más visibles para conseguir más reservas» (Ibid.). Por su parte, los huéspedes dispondrían de nuevos filtros de búsqueda de las ofertas que tengan las políticas de cancelación más flexibles; con ello, serán menos visibles en las búsquedas tanto las ofertas como los anfitriones que no quieran o puedan aceptar cancelaciones de última hora y pérdidas de la reserva. Con estas medidas, Airbnb empuja a los anfitriones a asumir más riesgos y responsabilidades en una nueva época marcada por la incertidumbre, ofreciendo a cambio que estos aparezcan mejor clasificados en los resultados de búsqueda.

La promoción de «alquileres de larga estancia» es otro de los cambios notables registrados en los materiales de marketing y comunicaciones de Airbnb. Anteriormente los huéspedes reservaban para poder conseguir su «inmersión en la nueva comunidad y poder explorar su cultura durante las vacaciones». Ahora la plataforma dice que los huéspedes están buscando alquilar por periodos más largos como «apoyo a sus planes de teletrabajo y de traslado temporal por motivos laborales. Así el trabajo desde casa se ha convertido en el trabajo desde cualquier casa (Airbnb 2020e, cursivas añadidas)». Es posible que las ofertas más populares en tiempos de la pandemia fueran las que estaban disponibles por períodos de tiempo más largos, así como aquellas que ofrecen «privacidad y distancia social» y que admiten mascotas. Con el fin de reducir los contactos personales, Airbnb 
ha recomendado a sus anfitriones que alarguen el tiempo de estancia de las reservas y ofrezcan a los huéspedes modalidades de «auto registro on-line». Sin embargo, los debates en el ACC revelan que hay anfitriones que quedan excluidos por no disponer de una propiedad que les permita optar por alinearse con el nuevo modelo. Los anfitriones que ofrecen una habitación o una cama en su propia vivienda no podrían cumplir con el requisito impuesto por Airbnb de distancia social o física permanente al alojar a los huéspedes; por tanto, estos no encajan en la nueva modalidad en la que se ofrece «trabajar desde cualquier casa». Y en muchos casos, tampoco los anfitriones están necesariamente dispuestos a alojar a personas por períodos prolongados, particularmente en las inciertas circunstancias creadas por la pandemia, tal como pudo leerse en muchos comentarios del blog del ACC. Quedan por estudiar las implicaciones de este cambio en la composición de la base de usuarios de Airbnb y en el tipo de ofertas publicitadas. Lo que sí puede señalarse con claridad en estos momentos, es que el interés de Airbnb por las «estancias prolongadas» está en línea con su reciente desarrollo de un «ecosistema centrado en las plataformas» que favorece a un grupo de anfitriones específico. Aquellos que sean capaces de capitalizar sus activos en vivienda propia para generar un flujo de ingresos más estable, serán también quienes contribuyan a incrementar la escala y las ganancias en las operaciones de Airbnb (van Doorn 2020, 13; para la «profesionalización privilegiada», véase también Bosma 2021).

\section{Desinfección de la vivienda y tratamiento de los casos de huéspedes infectados}

Las prácticas laborales de Airbnb también han registrado un cambio de enfoque fundamental en el último año. Hubo varios intentos de «profesionalizar» el trabajo doméstico y las interacciones entre usuarios aplicando nuevos protocolos y estándares, así como introduciendo cambios en la estructura de la plataforma. La «profesionalización» comporta la existencia de una estrategia implementada por Airbnb con el fin de redefinir y controlar las prácticas en el trabajo, como respuesta a diversas presiones sociales y económicas que se han hecho más evidentes durante la crisis sanitaria mundial ocasionada por la Covid-19. El 7 de abril de 2020, Airbnb anunció que aplicaría varios protocolos sanitarios y de seguridad en los meses subsiguientes y que, además, esperaba que sus usuarios cumplieran con las recomendaciones, leyes y políticas para viajeros emitidas por los gobiernos locales y nacionales (Airbnb 2020f). Para seguir haciendo uso de la plataforma, los anfitriones y los usuarios debían comprometerse a usar una mascarilla o cubierta facial y mantener en todo momento una distancia entre personas de 2 metros. Las nuevas normas generaron un considerable debate entre los anfitriones de los lugares en donde la prevalencia del virus no era extendida y cuyas medidas sanitarias y de seguridad eran más laxas (por ejemplo, en Nueva Zelanda).

Además, se recomendó a todos los anfitriones la adopción del «proceso de limpieza avanzada» en cinco pasos, que pasó a ser medida de obligado cumplimiento a partir del 20 de noviembre de 2020 (excepto para los anfitriones en China; respecto a Airbnb en China, véase Minca y Roelofsen 2019). Los anfitriones que no pudieran demostrar el cumplimiento de las medidas de seguridad (incluyendo el "proceso de limpieza avanzada») fueron informados de que sus reservas no serían aceptadas en lo sucesivo, quedando suspendida la publicación de sus ofertas, o retiradas éstas de Airbnb (Airbnb 2021). Los huéspedes que incumplieran (reiteradamente) las pautas de seguridad no tendrían derecho a un reembolso en el caso de que sus anfitriones cancelaran la reserva por dicho incumplimiento. Por último, se recomendó a los «anfitriones» que tanto el «equipo encargado del hospedaje» como los asociados en la limpieza siguieran los nuevos protocolos. Aquellos anfitriones que cumplieran el protocolo recibirían una estrella que aparece destacada junto al texto descriptivo de su oferta de alojamiento (Airbnb 2020g), de manera similar a los símbolos empleados en otros programas que indican "estatus", tales como las recompensas a los «Superhosts» (véase Roelofsen y Minca 2018). Por otro lado, los huéspedes estarían en condiciones de identificar y reservar los alojamientos incluidos en este programa tan pronto como los anfitriones se suscribieran. 
El control y la determinación de las modalidades de trabajo en el ecosistema de Airbnb es establecido a partir de la prescripción de un ámbito, una escala y unos límites para el trabajo doméstico y el hospedaje. Airbnb especifica qué cosas deben limpiarse, con qué frecuencia, por quién y con qué productos o materiales. También se dan instrucciones precisas sobre la interacción social entre anfitriones y huéspedes. Como ya ha sido mencionado, en todo momento el contacto físico o personal debe evitarse, al igual que debe mantenerse la distancia. Además, la compañía informó que se ha asociado con plataformas de servicios de limpieza con el fin de «facilitar una limpieza más rápida y mejorada». Es posible que muy pronto se ofrezcan «recompensas» para quienes externalicen esta clase de trabajo, como ya ocurre con los anfitriones que son «recompensados» si cumplen con los «protocolos de limpieza mejorada». Así, en las preferencias de búsqueda de los huéspedes podrían aparecer en los primeros lugares las ofertas del alojamiento que haya sido limpiado por los equipos «profesionalmente» certificados de Airbnb. Tal como ya lo publicitan Hyatt, Hilton y otras grandes cadenas hoteleras que aparecen en la web del Consejo Mundial de Viajes y de Turismo, Airbnb está comprometida con los estándares y protocolos de higiene y limpieza que le permitirán operar en las circunstancias actuales de «nueva normalidad» (WTTC 2021). La plataforma se ha asociado también con conocidas empresas de la industria química tales como Diversey, RB y Dettol, y recomienda a los anfitriones que adquieran sus productos y los utilicen en la limpieza de sus alojamientos (Airbnb 2020h; 2021a). Aun cuando asociarse con estas empresas y con su imagen pública podría ayudar a incrementar la confianza y la credibilidad en tiempos de la pandemia, la estrategia parece contradecirse con el modelo de negocio de Airbnb. Desde hace más de una década, éste se ha basado en preferir la experiencia idealizada de alojarse en las casas de personas desconocidas a la de hospedarse en una habitación de hotel corriente (y desinfectada) (Minca y Roelofsen 2019).

Existe un nivel aún más profundo para la desinfección del alojamiento en los casos en que el virus puede estar presente. Cuando los anfitriones o los huéspedes presentan síntomas o resultan positivos en una prueba de COVID-19, se les pide que sigan una serie de pasos establecidos por Airbnb (Airbnb 2021i). Estos incluyen diversos itinerarios en el caso de que los anfitriones y los huéspedes hayan tenido contacto estrecho o compartido el espacio de hospedaje. Cuando exista sospecha de infección o se obtenga un resultado de test positivo, se recomienda a ambos grupos de usuarios buscar atención médica, ponerse en contacto con las autoridades y también, informar a Airbnb de su estado de salud (lbid.). No es posible detallar aquí la extensa lista de pasos a seguir ante esta situación. Sin embargo, se han dado varios casos de suspensión de las cuentas de usuario de manera que los anfitriones o huéspedes quedan inhabilitados para reservar nuevas estancias en la plataforma de Airbnb durante un tiempo. Sus cuentas de usuario solo serán reactivadas cuando Airbnb reciba confirmación válida de que "se puede volver a hospedar o viajar». Asimismo, se aconseja a los anfitriones y a los huéspedes que «no envíen información sensible ni relacionada con cuestiones de salud (por ejemplo, certificados médicos)» (Ibid.). No obstante, la realización de estos trámites permite a Airbnb obtener y recoger datos sensibles acerca del historial sanitario de sus miembros.

La compañía ha anunciado recientemente que está preparando una Declaración de Seguridad Sanitaria que, por ahora, es una herramienta voluntaria que habilita al anfitrión a «solicitar al huésped que firme una declaración de no tener los síntomas comunes de COVID-19 y desconocer si han sido expuestos al virus» (Airbnb 2021b). La crisis sanitaria ha abierto la posibilidad de extraer y apropiarse de los datos (biométricos) de los anfitriones y los huéspedes conforme a unos principios de autodisciplina y autogestión de los cuerpos que ahora se están aplicando a los miembros de la plataforma (véase Roelofsen y Minca 2018). La retórica basada en la comunidad (de viajeros) que acogía la promesa de «vivir como la gente del lugar» ha sido reemplazada por una particular atención al saneamiento y el distanciamiento. A ello se suma la creciente estandarización de un conjunto de prácticas que han terminado por transformar una forma de inducción biopolítica a las espacialidades de la intimidad del hogar en una forma reguladora de la vida de las personas y de las relaciones sociales de huéspedes y anfitriones. 


\section{Observaciones finales}

En vista de lo aquí observado, tal vez sea procedente añadir algunas notas a modo de conclusión. La primera es que la situación de emergencia por efecto de la pandemia ha puesto en evidencia la manera en que Airbnb se ha eximido de responsabilidad al suspender las normas existentes respecto a las políticas de cancelación estrictas; por causa de esto, fueron los anfitriones los que se vieron más afectados por las consecuencias adversas de la pandemia. Ello les ocasionó un trastorno importante, razón por la cual reaccionaron de manera colectiva contra los cambios dispuestos, aunque con éxito relativo. Al mismo tiempo, la crisis ha permitido a la plataforma diseñar, implementar y facilitar una política de cancelación por motivos de emergencia, la cual se ha traducido en interminables exigencias de flexibilidad y responsabilidad para con los anfitriones. Además, con la modificación de las funciones de búsqueda y la manera en que éstas privilegian la aparición de las ofertas que sí cumplen con la nueva política, la compañía ha ejercido (de manera discreta) su poder sobre los anfitriones.

En segundo lugar, los conceptos de «alojamiento» y «hospedaje» (elementos identitarios tradicionalmente importantes en la política de viajes de Airbnb) están siendo interpretados desde la llegada de la pandemia. En sus orígenes, la compañía presentaba la experiencia de alojarse en casa de un anfitrión como algo original y auténtico, la hospitalidad en contraposición a lo que ofrecían los hoteles y otros establecimientos similares. Airbnb ponía el acento en las posibilidades de esa nueva manera de viajar, que permitía relacionarse con la población local y vivir como ellos. Sin embargo, con la imposición de los nuevos estándares de limpieza y desinfección del alojamiento, la intervención de personas ajenas a la vivienda (antes considerada como un atractivo) se somete ahora a una vigilancia más estricta. A todo ello se añade un mayor nivel de control que es, hasta cierto punto, comparable con el control que suele ejercerse en el ámbito de la hostelería comercial.

Los cambios recientemente operados en la infraestructura de la plataforma y en sus protocolos facilitan la exposición, extracción y apropiación de los datos relativos al «trabajo de hospedaje», particularmente de aquellos que tienen que ver con las operaciones de limpieza y las interacciones presenciales. La externalización de los trabajos de limpieza en servicios profesionales aprobados por Airbnb podría ir en contra de los anfitriones que (solo pueden permitirse) realizar su propia limpieza o encargar el trabajo a terceros. Es probable que esta política altere tanto las relaciones establecidas por contrato como la dinámica de poder entre Airbnb y las administradoras inmobiliarias o las empresas de limpieza, pues éstas habían convenido previamente sus términos y condiciones con los arrendadores de corta estancia. Todas estas son novedades que generan dudas acerca de la estandarización y la subcontratación laboral adoptada por Airbnb, en la medida en que ocasionarán problemas con la legislación vigente y otras directrices (nacionales) del derecho laboral referidas a la protección de los trabajadores en el sector turístico (véase también Roelofsen y Minca 2018; loannides et al. 2021). Es cierto que muchos trabajos académicos sobre Airbnb se centran a menudo en la creación de una política para los alquileres de corto plazo con el fin de proteger el mercado de la vivienda y velar por el cumplimiento de las normas de salud y seguridad, así como de la fiscalidad. Pero quisiéramos resaltar aquí que todavía queda mucho por estudiar acerca de las condiciones laborales y el cumplimiento de sus leyes, particularmente en contextos en los que «prevalecen los bajos salarios, la explotación y una insuficiente protección, como ocurre en las industrias del turismo y de la hostelería» (Bianchi and de Man 2021).

También merece investigarse la creciente tendencia, observada en Airbnb, a fomentar entre sus miembros la oferta de estancias de mediano y largo plazo para «huéspedes» que podrían ser residentes en las proximidades del alojamiento. Aun cuando siempre se ha presentado como una compañía que opera en el sector del turismo y la hostelería, ¿sería posible que Airbnb se esté transformando, a vista de todos, en una «inmobiliaria de plataforma» (Fields y Rogers 2019) que ofrece espacios de alquiler para los más diversos propósitos? ¿Y de qué manera ello podría afectar, en diferentes contextos, la oferta y el mercado de la vivienda, así como los precios de ésta? Por ejemplo, algunos agentes inmobiliarios escriben comentarios de blog sobre el incremento del valor de sus propiedades mientras especulan con las cinco estrellas que son como un «antecedente» de la valoración de los clientes de Airbnb. ¿Cuáles podrían ser las consecuencias de este cambio en comparación con el impacto que han tenido en las ciudades los alquileres de estancias cortas? ¿Y cuál será el perfil de los nuevos «anfitriones» de la plataforma en los próximos años? Los nuevos protocolos de Airbnb ¿serán insostenibles e insoportables para 
aquellos anfitriones cuyas viviendas no sean adecuadas o que no dispongan de tiempo ni dinero para invertir en los trabajos requeridos? Si volvemos a preguntarnos acerca del futuro de Airbnb, nuestro breve estudio pone en evidencia que, a pesar de todas las dificultades que comporta la restricción a la movilidad turística en tiempos de pandemia, están surgiendo nuevas oportunidades en los espacios vacíos que nos deja la crisis sanitaria. Será importante estar atentos al papel que tendrá que jugar la plataforma en la evolución de los conceptos de alojamiento y vida cotidiana, pero también del trabajo en el turismo y el mercado de la vivienda.

\section{Bibliografía}

AIRBNB (2016). Overview of the Airbnb Community in Berlin. [en línea]. Disponible en: https://www.airbnbcitizen. com/wp-content/uploads/2016/04/airbnb-community-berlin-en.pdf

AIRBNB (2017a). Read the report: Airbnb, Housing, and the City of Cambridge. [en línea]. Disponible en: https://news.airbnb.com/read-the-report-airbnb-housing-and-the-city-of-cambridge/

AIRBNB (2017b). The Positive Impacts of Home Sharing in Copenhagen. [en línea]. Disponible en: https://news. airbnb.com/the-positive-impacts-of-home-sharing-in-copenhagen/

AIRBNB (2020). Airbnb's Work to Protect its Community During the Coronavirus Outbreak. [en línea]. Disponible en: https://news.airbnb.com/update-on-extenuating-circumstances-policy-for-coronavirus/

AIRBNB (2020a). A letter to hosts. [en línea]. Disponible en: https://news.airbnb.com/a-letter-to-hosts/

AIRBNB (2020b). Superhost Relief Fund Provided Grants to 8,700 Homes and Experience Hosts. [en línea]. Disponible en: https://news.airbnb.com/superhost-relief-fund-provided-grants-to-8700-homes-and-experience-hosts/

AIRBNB (2020c). A People-to-People Marketplace. By Greg Greeley. [en línea]. Disponible en: https://news. airbnb.com/a-people-to-people-marketplace/

AIRBNB (2020d). More Flexible Reservations in Times of Uncertainty. [en línea]. Disponible en: https://news. airbnb.com/more-flexible-reservations-in-times-of-uncertainty/

AIRBNB (2020e). Work From Anywhere: How Airbnb \& Guests are Approaching Remote Working. [en línea]. Disponible en: https://news.airbnb.com/work-from-anywhere-how-airbnb-guests-are-approaching-remote-working/

AIRBNB (2020f). Airbnb's Enhanced Cleaning Initiative for the Future of Travel. [en línea]. Disponible en: https://news.airbnb.com/our-enhanced-cleaning-initiative-for-the-future-of-travel/

AIRBNB (2020g). Getting started with the 5-step enhanced cleaning process. [en línea]. Disponible en: https://www. airbnb.com/resources/hosting-homes/a/getting-started-with-the-5-step-enhanced-cleaning-process-186

AIRBNB (2020h). Introducing Airbnb Enhanced Clean. [en línea]. Disponible en: https://news.airbnb.com/introducing-airbnb-enhanced-clean/

AIRBNB (2020i). Your guest or host may have COVID-19. Now what? [en línea]. Disponible en: https://www. airbnb.com/resources/hosting-homes/a/your-guest-or-host-may-have-covid-19-now-what-168

AIRBNB (2021). What is Airbnb's 5-step enhanced cleaning process? [en línea]. Disponible en: https://www. airbnb.com/help/article/2809/what-is-airbnbs-5step-enhanced-cleaning-process

AIRBNB (2021a). Partnering with RB, the Makers of Lysol®, to Help Protect Hosts and Guests. [en línea]. Disponible en: https://news.airbnb.com/partnering-with-rb-the-makers-of-lysol-to-help-protect-hosts-and-guests/

AIRBNB (2021b). Airbnb Announces Health Safety Attestation to Support Responsible Travel. [en línea]. Disponible en: https://news.airbnb.com/airbnb-announces-health-safety-attestation-to-support-responsible-travel/

ALLYN, B.; SCHNEIDER, A. "Airbnb now a $\$ 100$ billion company after stock market debut sees stock price double". NPR, 2020 [artículo en línea]. [Fecha de consulta: 9 de febrero de 2021].

BARNS, S. Platform Urbanism. Singapore: Springer Singapore, 2020. DOI: https://doi.org/10.1007/978-981-329725-8

BIANCHI, R.V.; DE MAN, F. "Tourism, inclusive growth and decent work: a political economy critique". Journal of Sustainable Tourism, 2021, vol. 29, no. 2-3, págs. 353-371. DOI: https://doi.org/10.1080/09669582.2020.1 730862 
BOSMA, J. "Airbnb and Covid-19: Capturing the Value of the Crisis". Platform Labor, 2020 [artículo en línea]. [Fecha de consulta: 9 de febrero de 2021].

BOSMA, J. "Platformed professionalization: Labor, assets, and earning a livelihood through Airbnb". University of Amsterdam, Centre for Urban Studies Working Paper Series, 49, 2021.

BOSMA, J.; MOS, E.; DOORN, N. van, "Disrupting 'Business as Usual': COVID-19 and platform labour”. Futures of Work, 2021[artículo en línea]. №. 15. [Fecha de consulta: 9 de febrero de 2021].

COCOLA-GANT, A.; GAGO, A. "Airbnb, buy-to-let investment and tourism-driven displacement: A case study in Lisbon". Environment and Planning A: Economy and Space, 2019. DOl: https://doi. org/10.1177\%2F0308518X19869012.

DOLNICAR, S.; ZARE, S. "COVID19 and Airbnb - Disrupting the Disruptor". Annals of Tourism Research, 2020. DOI: https://doi.org/10.1016/j.annals.2020.102961.

FIELDS, D.; ROGERS, D. "Towards a Critical Housing Studies Research Agenda on Platform Real Estate". Housing, Theory and Society, 2021. vol. 38, no. 1, págs. 72-94. DOl: https://doi.org/10.1080/14036096.2019.1 670724

GIL, J.; SEQUERA, J. "The professionalization of Airbnb in Madrid: far from a collaborative economy". Current Issues in Tourism, 2020. DOI: https://doi.org/10.1080/13683500.2020.1757628.

GLUSAC, E. "In a Changed World for Travel, What Does Airbnb's Future Hold?" New York Times, 2020 [artículo en línea]. [Fecha de consulta: 9 de febrero de 2021].

IAQUINTO, B.L. "Tourist as vector: Viral mobilities of COVID-19". Dialogues in Human Geography, 2020. vol. 10, no. 2, págs. 174-177. DOI: https://doi.org/10.1177\%2F2043820620934250.

IOANNIDES, D.; GYIMÓTHY, S.; JAMES, L. "From liminal labor to decent work: A human-centered perspective on sustainable tourism employment". Sustainability, 2021. vol. 13, no. 2, págs. 1-15. DOl: https://doi. org/10.3390/su13020851.

MINCA, C.; ROELOFSEN, M. "Becoming Airbnbeings: on datafication and the quantified Self in tourism". Tourism Geographies, 2019. DOI: https://doi.org/10.1080/14616688.2019.1686767.

ROELOFSEN, M. "Performing 'home' in the sharing economies of tourism: The airbnb experience in Sofia, Bulgaria". Fennia, 2018. vol. 196, no. 1, págs. 24-42. DOl: https://doi.org/10.11143/fennia.66259.

ROELOFSEN, M.; MINCA, C. "The Superhost. Biopolitics, home and community in the Airbnb dream-world of global hospitality". Geoforum, 2018. vol. 91, págs. 170-181. DOl: https://doi.org/10.1016/j.geoforum.2018.02.021.

SCHAAL, D. "The Future of Short-Term Rentals After the Pandemic and an Airbnb IPO". Skift, 2020 [artículo en línea]. [Fecha de consulta: 9 de febrero de 2021].

SEMI, G.; TONETTA, M. "Marginal hosts: Short-term rental suppliers in Turin, Italy". Environment and Planning A, 2020. DOI: https://doi.org/10.1177\%2F0308518X20912435.

UNWTO, "How are countries supporting tourism recovery?" UNWTO Briefing Note - Tourism and COVID-19, 2020. $1^{\text {a }}$ ed., $n^{\circ}$ 2, págs. 1-28. DOI: https://doi.org/10.18111/9789284421893.

VAN DOORN, N. "A new institution on the block: On platform urbanism and Airbnb citizenship". New Media \& Society, 2020. vol. 22, no. 10, p. 1808-1826. https://doi.org/10.1177/1461444819884377

VAN DOORN, N. "Platform labor: on the gendered and racialized exploitation of low-income service work in the 'on-demand' economy". In: Information, Communication \& Society. 2017. Vol. 20, no. 6, pages 898-914. ISSN: 1461-4448. DOI: https://doi.org/10.1080/1369118X.2017.1294194.

WILSON, J.; GARAY-TAMAJON, L.; MORALES-PEREZ, S. "Politicising platform-mediated tourism rentals in the digital sphere: Airbnb in Madrid and Barcelona". Journal of Sustainable Tourism, 2021. DOI: https://doi.org/1 0.1080/09669582.2020.1866585.

WTTC, "Safe Travels: Global Protocols \& Stamp for the New Normal" World Travel and Tourism Council, 2020. [artículo en línea]. 
Citación recomendada: ROELOFSEN, Maartje; MINCA, Claudio. Alojamientos desinfectados y cuerpos sanos: reflexiones sobre la respuesta de Airbnb a la pandemia. Oikonomics [online]. Mayo 2021, no. 15, pp. 1-10. ISSN: 2339-9546. DOI: https://doi.org/10.7238/o.n15.2104

Los textos publicados en esta revista están sujetos -si no se indica lo contrario- a una licencia de Reconocimiento 4.0 Internacional de Creative Commons. Puede copiarlos, distribuirlos, comunicarlos públicamente, hacer obras derivadas siempre que reconozca los créditos de las obras (autoría, nombre de la revista, institución editora) de la manera especificada por los autores o por la revista. La licencia completa se puede consultar en https://creativecommons.org/licenses/by/4.0/deed.es_ES.
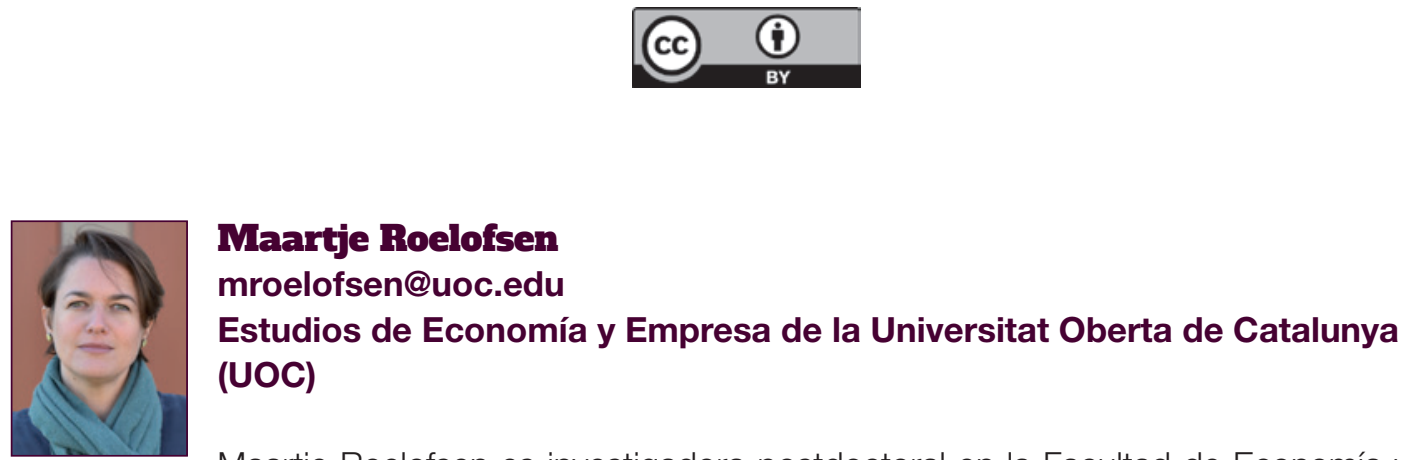

Maartje Roelofsen es investigadora postdoctoral en la Facultad de Economía y Empresa de la Universitat Oberta de Catalunya en España. Sus investigaciones versan sobre los impactos socioespaciales de las tecnologías digitales, específicamente en el ámbito del turismo. Tomando Airbnb como estudio de caso, ha indagado sobre el papel de la plataforma en la transformación de las ideas y las prácticas relacionadas con la noción del alojamiento. Su trabajo más reciente analiza la manera en que los usuarios de las plataformas se sirven de ellas para reforzar su capacidad de acción política con el fin de cuestionar y cambiar las modalidades de gobernanza de la empresa.

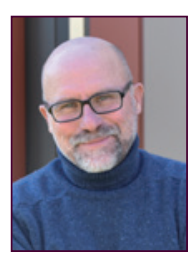

\section{Glaudio Minca claudio.minca@unibo.it \\ Departamento de Historia y Culturas - Unidad de Geografía Alma Mater Studiorum - Universidad de Bolonia}

Claudio Minca es profesor de Geografía en el Departamento de Historia y Culturas de la Universidad de Bolonia en Italia. Sus investigaciones se centran en tres grandes temas: la espacialización de la (bio)política, el turismo y las teorías sobre el viaje en la modernidad, y la relación entre el conocimiento moderno, el espacio y el paisaje en la geografía postcolonial. Recientemente, ha trabajado sobre las geografías de las prisiones, y en particular, en las de los campos de refugiados de Serbia y la región de los Balcanes. Actualmente es profesor visitante en la Facultad de Economía y Empresa de la Universitat Oberta de Catalunya. 